\title{
A TAILORED EXERCISE PROGRAM VERSUS GENERAL EXERCISE FOR A SUBGROUP OF PATIENTS WITH LOW BACK PAIN AND MOVEMENT CONTROL IMPAIRMENT: SHORT-TERM RESULTS OF A RANDOMISED CONTROLLED TRIAL
}

Jeannette Saner, MSc PT

ZHAW School of Health Professions, Institute of Physiotherapy, Winterthur, Switzerland

CAPHRI School for Public Health and Primary Care, Maastricht, the Netherlands

Judith M Sieben, PhD

CAPHRI School for Public Health and Primary Care, Maastricht, the Netherlands

Maastricht University, Dept. of Anatomy \& Embryology, Maastricht, the Netherlands

Jan Kool, PhD, PT

ZHAW School of Health Professions, Institute of Physiotherapy, Winterthur

Switzerland

Hannu Luomajoki, PhD, PT

ZHAW School of Health Professions, Institute of Physiotherapy, Winterthur

Switzerland

Carolien HG Bastiaenen, PhD, PT

CAPHRI School for Public Health and Primary Care, Maastricht, the Netherlands Maastricht University Dept. of Epidemiology, Maastricht, the Netherlands

Rob A de Bie, PhD, PT

CAPHRI School for Public Health and Primary Care, Maastricht, the Netherlands Maastricht University Dept. of Epidemiology, Maastricht, the Netherlands

Address for correspondence

Jeannette Saner

ZHAW Departement Gesundheit, Institut für Physiotherapie,

Technikumstrasse 71, Postfach 8401, Winterthur, jeannette.saner@zhaw.ch ${ }_{2}$ Tel + Fax +41 5893463 70, www.gesundheit.zhaw.ch

Keywords: randomised controlled trial, movement control impairment, exercise, low back pain, clinical trial, posture, rehabilitation, patient specific functional scale,

The project was supported by the Swiss National Science Foundation (SNSF). (Project no. 127240)

The trial was prospectively registered (ISRCTN80064281), ethical approval was obtained from the Swiss Ethics Committee KEK-ZH-NR: 2010-0034/5 


\section{Abstract}

\section{Background:}

Exercise is an effective treatment for patients with sub-acute and chronic low back pain (LBP). Patients with a movement control impairment (MCI) can be diagnosed as a subgroup of patients with LBP. Unknown is which exercise intervention is most beneficial for this subgroup.

This study assessed the short-term effect of a specific exercise program targeting movement control impairment versus general exercise treatment on disability in patients with LBP and $\mathrm{MCl}$.

Methods: In a multicentre parallel group randomised controlled pragmatic trial, patients with sub-acute and chronic LBP were included. Further inclusion criteria were disability of $\geq 5$ points on the Roland-Morris Disability Questionnaire and $\geq 2$ positive tests out of a set of 6 movement control impairment tests.

A total of 106 patients were randomly assigned to either tailored movement control exercise intervention (MC, $\mathrm{n}=52$ ) or a general exercise intervention ( $\mathrm{GE}, \mathrm{n}=54$ ); both $9-18$ individual treatment sessions, over a maximum of 12 weeks. . The primary outcome was disability measured with the Patient Specific Functional scale (PSFS). Secondary outcome was the Roland-Morris disability scale (RMDQ). Measurements were taken pre- and posttreatment. Results: No significant difference was found following the treatment period. Baselineadjusted between-group mean difference for the PSFS was 0.5 (SD $=0.5 ; p=0.32$ ) in favour of MC exercises. The Roland-Morris Disability Questionnaire revealed a significant, but not clinically relevant, between-group difference of 2.0 points $(S D=0.8 ; p=0.01)$.

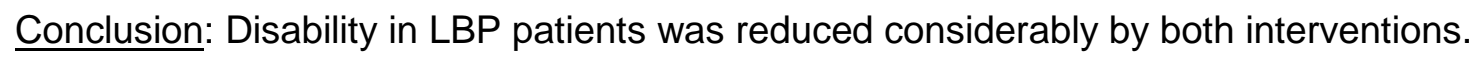
However, the limited contrast between the two exercise programs may have influenced outcomes. 


\section{$\underline{\text { Introduction }}$}

Societal cost of treatment and absence from work due to low back pain (LBP) are a major economic burden (Airaksinen et al., 2006); in Switzerland, an estimated fourteen billion Swiss Francs (15 billion US dollars) are spent annually on direct and indirect costs due to LBP. In 2007, $41 \%$ of the working population in Switzerland reported LBP during the previous month (SNF, 2009). In most cases a specific diagnosis cannot be identified and the condition is labelled as non-specific low back pain (NSLBP)(Grob et al., 2007). Due to the heterogeneity of this patient group, it has been recommended to focus research on defining and treating subgroups (Foster et al., 2011).

Within the spectrum of NSLBP, a subgroup of patients with a movement control impairment $(\mathrm{MCl})$ can be identified. These patients present with mechanical pain, related to movement and positioning of the spine, in combination with an impairment of control during movement of the lumbar spine. To allow a more specific categorisation, the condition is further classified based on the direction of the reported control deficit, i.e. flexion, extension, frontal plane or multidirectional, as described by O'Sullivan (O'Sullivan, 2005). The rationale of $\mathrm{MCl}$ is based on the concept of repeated mechanical overload of tissues in the lower back. The clinical diagnosis of these categories showed a good reliability (Dankaerts et al., 2006; Fersum et al., 2010).

Definition and treatment of subgroups requires plausible explanations for concepts or models to underpin targeted interventions. The identification of subgroups requires clinically feasible and reliable screening procedures (Foster et al., 2011). The validity of the clinical diagnosis of the subgroup with $\mathrm{MCl}$ and its functional representation is gaining increasing support (Dankaerts \& O'Sullivan, 2011; Fersum et al., 2009). To further improve the screening procedure for $\mathrm{MCl}$, six active movement tests have 
been identified in a previous study which showed substantial intra- and interrater reliability and represent the clinical classification as described above (Luomajoki et al., 2007); validity of the test series was supported by research, showing that two or more positive tests, out of a total of six tests, could distinguish between patients with LBP and healthy controls (Luomajoki et al., 2008). Results of a case series, in which patients were classified as $\mathrm{MCl}$ by means of the set of six tests, showed significant improvement in disability and pain when patients were given tailored exercises that aimed to improve their control impairment (Luomajoki et al., 2010). However, the direct cause-effect relationship between $\mathrm{MCl}$ and NSLBP remains unclear.

While exercise as a treatment modality has been shown to be ineffective in the acute phase of LBP ( $<6$ weeks) (Airaksinen et al., 2006; Hayden et al., 2005a; Hayden et al., 2005b; Hayden et al., 2005c), several studies support the positive effect of exercise on pain and function in sub-acute and chronic pain patients (Hayden et al., 2005c). The question remains which exercises are most beneficial for which patients. Specific exercise programs to treat $\mathrm{MCl}$ are widely used in physiotherapy practice. In these programs, the impaired control is addressed with individually tailored exercises, according to the classification based on $\mathrm{MCl}$ tests. The postulated rationale for a treatment program for $\mathrm{MCl}$ are manifold: A positive influence on mechanically induced pain is assumed, due to a decrease of the load on nociceptive innervated tissues. Furthermore, improved activity in daily life, due to decreased disability and prevention of LBP recurrences, due to increased awareness of body positions (Kavcic et al., 2004; Moseley, 2008; Solomonow et al., 2003; Solomonow et al., 2001) may explain a positive effect. However, evidence for the effectiveness of this treatment in a healthcare setting is still lacking. 
A general exercise program has previously been tested in a sub-acute and chronic population in comparison with low-load stabilisation exercises plus general exercise (Koumantakis et al., 2005). Results showed that, in the short term, disability was reduced to a greater extent by general exercise alone. However, in this study patients with all types of NSLBP were included, not only patients with NSLBP and MCI. Comparison of an individually tailored, specific $\mathrm{MCl}$ treatment against other active treatments for this subgroup is lacking. This article reports the short-term results of a pragmatic randomised controlled trial $(\mathrm{RCT})$ in outpatient physiotherapy settings on disability in LBP patients with $\mathrm{MCl}$, testing the effectiveness of an individualised exercise program targeting $\mathrm{MCl}$ versus general exercise treatment.

\section{Methods}

\section{Trial Design}

A multicentre parallel group pragmatic RCT was executed in five hospital outpatient departments and eight private practices in Switzerland. Patients were recruited between August 2010 and February 2012 through referrals from hospitals and general practitioners, as well as through advertisements aimed at staff and students of the Zurich University of Applied Sciences, Winterthur. The study protocol has been published (Saner et al., 2011).

\section{Participants}

Patients (age 18 to 75 ) presenting with sub-acute or chronic LBP persisting longer than six weeks were invited to participate in the baseline screening and assessment procedure. Included were patients with $\mathrm{MCl}$ complaints, in which pain was provoked by movements and static positions of the spine (Mannion et al., 2010). At baseline 
assessment a minimum score of 5 points on the Roland-Morris Disability

Questionnaire (RMDQ) was required to ensure at least a minor level of disability

(Pengel et al., 2004). At least two positive tests out of six MCI tests were required for inclusion (Luomajoki et al., 2008, 2010). Patients were excluded (1) when spinal pathology was suspected or diagnosed (fractures, carcinoma, nerve root compression with neurological signs, e.g. reflex loss, muscle weakness); (2) in case of previous spinal surgery or spondylodesis; (3) if comorbid health conditions prohibited exercise training. (4) To focus on patients with LBP responding to movement, we excluded patients with constant pain and pain below the knee. (5) To avoid confounding with high psychosocial factors, patients with scores of more than 130 on the Örebro Musculoskeletal Pain Screening Questionnaire and more than 3 months of sick leave due to LBP, were excluded (Linton \& Boersma, 2003). For more details see flow chart Fig. 1.

\section{Randomisation and Blinding}

Once informed consent was signed, baseline assessments were taken by an independent and specially-trained physiotherapist. The randomisation schedule used to assign participants to either movement control (MC) or general exercise (GE) treatment group was generated electronically using a block size of four. Allocation to treatment of eligible patients was performed (by means of a telephone contact) by a research assistant of the university, who was not otherwise involved in the study. Blinding of participants and physiotherapists to allocation was not possible due to the nature of the treatment. Outcome assessors and data analysts were blinded to treatment allocation and were not involved in the interventions. The involved therapists and researchers were masked from the outcome measurements and trial 
results, except for physiotherapists in the MC group, who were informed of the results of the initial six physical MCI tests in order to apply $\mathrm{MCl}$ direction specific treatment.

\section{Intervention}

Participants in both groups were scheduled for treatment in the outpatient departments of the clinics and practices where they had been recruited.

Movement control (MC) treatment, as illustrated in Appendix, focused on specific active exercises to improve the individual movement control impairment as diagnosed previously. Initially, participants learned to control the impaired movements (either/and in flexion/extension/frontal plane) in closed-chain positions. They then progressed to open-chain positions and to exercises with controlled movements and increased load. Postural and movement awareness was practiced in various situations. Strength training was allowed once control of pain provoking movements was achieved.

General exercise (GE) treatment, as illustrated in Appendix, followed a non-specific standardised program, in which strength and endurance of muscles of the lumbar/pelvic region and legs were exercised. All relevant muscle groups (abdominals, erector spinae, gluteals, quadriceps and hamstrings) were included in each treatment session. The progression of exercises followed the guidelines of the American College of Sports Medicine (Whaley, 2006). This exercise intervention was chosen as the control intervention because of its credibility as a treatment alternative for movement-related NSLBP (Hides \& Stanton, 2012).

Treatment description: All participants received individual treatment sessions of 30 minutes, generally twice per week, for a maximum of 12 weeks. Recommendations of twice per week and a maximum of 12 weeks in total were chosen in line with current 
clinical practice (which includes 9-18 therapy sessions). This allows enough time for a comprehensive treatment which is effective in achieving optimal changes of movements and tissues.

Treatment progression followed a pragmatic approach and was determined by the clinical judgement of the physiotherapist. In each session, a timespan of maximal 10 minutes was allowed for other physiotherapy applications; duration (minutes) and types of interventions were recorded. All participants should have mastered at least three home-exercises by the end of treatment. Two regular exercise sequences per week of self-directed home-exercise were strongly recommended for the following year.

The main contrast between the two treatments was the instruction of specifically and individually tailored movement control exercises applied in the MC group, as opposed to the generalised approach in the GE group.

The physiotherapists treating the MC group were either qualified to OMT (Orthopaedic manual therapy) standards or novices working under supervision of experts at the university.

All therapists underwent at least four hours of training on the study procedures and received a manual of exercise interventions. Therapists reported on exercise programs, number of home exercises and minutes of other interventions for each patient in a written log.

\section{Baseline Descriptives}

Demographic data, including age, sex, height, weight, sports activities, workload, work status, medication usage and duration of symptoms, were documented. Descriptive measures also included the Fear-Avoidance Beliefs Questionnaire 
(FABQ)(Sieben et al., 2005; Staerkle et al., 2004) and the Graded Chronic Pain Scale (GCPS) version 2.0 with subscales for pain intensity, disability and state of chronicity (Turk, 2011).

\section{Outcome Measures}

Measurements were taken at baseline and after treatment (see flowchart Fig1.). The primary outcome was LBP-related disability as measured with the Patient-Specific Functional Scale (PSFS) (Hall et al., 2011; Stratford P, 1995). PSFS was chosen as the primary outcome, because it represents the clinical reality and personal relevance for patients, as it refers to the activity which is most important in limiting daily life. Additionally, clinimetric studies regarded PSFS as more responsive than RMDQ in patients with mild NSLBP (Horn et al., 2012; Pengel et al., 2004).

The secondary outcome measure was disability, as measured with the Roland-Morris Disability Questionnaire (RMDQ). More details on the outcome measures are described in the study protocol (Saner et al., 2011).

\section{Sample Size Calculation}

Based on a previous case series (Luomajoki et al., 2010), sample size was calculated in order to detect a mean difference between the two groups of 0.9 points on the PSFS, with an assumed standard deviation of 1.5 points. With alpha set at 0.05 and statistical power at $90 \%, 48$ participants were required in each group. Accounting for a drop-out rate of $10 \%, 106$ participants were included.

\section{Data Analysis}

Descriptive statistics of demographic data and clinical measures were performed. 
Given the finding that on the PSFS the correlation between the average of three activities and the first activity mentioned by the patient was very high (0.9), the value of only the first activity was used in further analysis.

Analyses were performed according to intention-to-treat principles. Missing values after treatment were substituted by group average. For between-groups analyses, mean differences between baseline and short-term measurements, their SDs and confidence intervals were calculated, followed by a one-way between-group analysis of variance for each clinical outcome. Influences of baseline differences between the groups, and of potentially confounding variables were assessed with analysis of covariance. All analyses were conducted using IBM SPSS Statistics 20. Two-sided significance for all values was set at $p<0.05$.

Based on literature, a minimal clinically important difference for slightly disabled LBP participants was set a priori, at $30 \%$ of baseline score for PSFS and RM (Dworkin et al., 2009; Maughan \& Lewis, 2010; Saner et al., 2011). Relative risk (RR) and number needed to treat (NNT) were calculated.

\section{$\underline{\text { Results }}$}

\section{Participants}

A total of 201 patients were evaluated for eligibility. Reasons for exclusion $(n=48)$ are described in the flow chart in figure 1. A total of 153 patients were assessed for baseline variables, of which 47 were excluded, mainly because of not meeting minimal requirements for $R M D Q(n=24)$ and $M C$ test series $(n=12)$. The remaining 106 participants were randomized $(\mathrm{MC}=52, \mathrm{GE}=54)$. Baseline characteristics across groups (see table 1) were well balanced, except that the MC group had longer pain duration. 
Insert Figure 1: Flow chart about here

Measurements after treatment were taken in 41/49 MC/GE cases respectively. Three participants in the MC group and two in the GE group either withdrew from the study or were lost to follow up. Seven participants in the MC group and three in the GE group finished treatment but were not assessed post-treatment. Baseline characteristics did not differ between assessed and non-assessed participants, except for the duration of pain.

Insert Table 1 Baseline demographic data and baseline results of questionnaires about here

\section{Adherence}

Seventy-nine $(74.5 \%)$ treatment logs $(\mathrm{MC}=41 ; \mathrm{GE}=38)$ were returned by physiotherapists for analysis. The mean number (SD) of treatment sessions for MC and GE groups was 8.4(2.9) and 8.8(3.4) respectively; the number of home exercises recommended at end of treatment was 3.9(1.3) and 5.0(2.7), respectively. Participants in both groups started with a mean number of impaired movement control tests of 3.9; after treatment the MC group improved to a mean of 1.8 and the GE participants to 2.8 positive tests.

\section{Primary outcome}

There was no statistically significant difference on the PSFS between the two exercise groups after treatment ( $p=0.32$; see table 2). Based on literature and 
baseline differences, pain intensity, pain duration and baseline PSFS were tested for their influence on group differences (primary outcome) using univariate analysis of variance. The baseline PSFS was identified as a potentially influencing factor $(p<0.001)$. Analysis of covariance (ANCOVA) showed no significant change on the primary outcome, however.

Insert Table 2 Results of disability scores about here

\section{Secondary outcome}

For the RM a significant difference in mean change scores between the two groups was found $($ mean $=2.0 ; 95 \% \mathrm{Cl}=0.4-3.5 ; p=0.01)$.

\section{Minimal Clinically Important Difference}

The minimal clinically important difference, defined a priori as $30 \%$ of the baseline scores, was 1.26 and 2.7 for the PSFS and RM respectively (Dworkin et al., 2009). Concerning the absolute number of participants with a clinically significant change, no significant difference could be found at follow-up for both variables (Table 2). However, as table 3 shows, relative risk, the factor reflecting improvement, differed in favour of the MC group for both outcomes with PSFS/RM;1.25/1.39 respectively. The average number of participants who need to be treated to provide improvement with $\mathrm{MC}$ is shown as numbers needed to treat (PSFS/RM;7/5).

Insert Table 3 Participants with a minimal clinical important difference about here 


\section{Co-interventions}

Four participants ( 1 in GE and 3 in $M C$ ) reported additional self-financed treatments (acupuncture, massage) during the treatment period.

\section{Work Status and Return to Work}

Of the 12 participants who were on sick leave due to LBP at baseline, eight returned to unrestricted work post-treatment. One participant in the GE group (id73) remained on restricted work status. Three participants who were initially on sick leave withdrew from the study for personal reasons. Work status post-treatment was not reported by three participants.

\section{Discussion}

This multicentre randomised controlled trial is, as far as we know, the first study to uniquely include NSLBP participants with $\mathrm{MCl}$. Differences in primary outcome between the MC and GE groups were small and insignificant. Only between-group differences in improvements on the Roland-Morris questionnaire, the secondary outcome, reached significance. Both groups improved substantially in all treatment outcomes. Given the positive natural course of NSLBP, this improvement was to be expected.

\section{Methodological Limitations}

Several limitations of this study must be noted. Since recruitment from participating practices was below expectations, thirty participants were recruited among staff and students of the university through an additional internal advertisement. These 
participants were not referred by a physician. However, analysis showed that these participants were comparable to referred patients for baseline characteristics and outcomes.

Sixteen participants were not assessed post-treatment. Six withdrew from the study or developed other illnesses. Final assessment after participants had completed their treatment was not possible in ten cases for logistic reasons, since the procedure required an additional consultation with an independent assessor.

To improve recruitment from participating physiotherapists, the protocol allowed for a maximum of ten minutes per treatment session to be used for other techniques, such as muscle stretching and mobilisation. Log books showed a wide variety of additional interventions, which was comparable in both groups. Our research aim was to evaluate, whether for a specific subgroup of patients with $\mathrm{MCl}$, a $\mathrm{MCl}$ intervention is more effective than a general exercise physical therapy program. These strict design choices may have diminished the treatment contrast between groups. For example, a comparison of $\mathrm{MCl}$ exercise versus usual care by a physician, prescribing physical therapy only in a few cases, might yield larger between-group differences. However, the design used for this RCT to our opinion best reflects current treatment choices in everyday physical therapy practice.

Other possible influences on the results could originate from treatment frequency and number of treatment sessions. A treatment frequency of 2 sessions per week was a recommendation rather than a rule; the number of sessions was reported in the log book and showed no difference between the groups. Similarly the number of home exercises is comparable in both groups. Controlling the quality of and adherence to exercise during the treatment phase was up to the physiotherapist. However, we 
think the influences are comparable in both groups and we have no reason not to believe the reports of patients or therapists.

\section{Theoretical and Clinical Implications}

We used two measures of disability (PSFS, RMDQ). PSFS did not show significant between-group differences, while difference in RMDQ was significant. The PSFS was chosen as primary outcome, because in previous research sensitivity to change was reported to be higher than for the RMDQ in participants with low levels of disability (Beurskens et al., 1999; Pengel et al., 2004). With the PSFS the patient individually selects his limited activities, which we expected to be more responsive for disability outcome.

The RMD questionnaire, on the other hand, assesses the disability over the past 48 hours using 24 standard items, to be valued in a dichotomous manner. With a mean of eight to nine points at baseline, our patient sample was only mildly affected. Although a floor effect could be expected, the short term between-group difference in RMDQ improvement was significant in favour of the MC group.

We had planned to evaluate disability using the average of three PSFS activities. However, several participants were unable to name three activities. A frequent reason was, that participants mentioned activities that were not currently performed (snow shovelling or digging the garden), making these activities unsuitable for the assessment of disability during the past week. Therefore, we assessed correlations and found a very high correlation (0.9) between the first activity mentioned and the average of the maximal three activities. To ease the evaluation process, we proceeded with only the first activity mentioned in all further analysis. 
Between-group differences for the minimal clinically important change were smaller than the a priori set level of $30 \%$. However, on evaluation of participants with a minimal clinically important change of improvement, $77 \%$ of participants within the MC group improved more than the determined 30\% for both outcomes. The general exercise group improved $61 \%$ for PSFS and 55\% for RMDQ above minimal clinical importance. This resulted in numbers needed to treat of $7 / 5$ patients in favour of the movement control treatment, when measured with PSFS or RMDQ respectively.

This study showed that in the short-term, movement control exercise was not significantly superior to general exercise for patients with $\mathrm{MCl}$. One reason could be the low contrasts between the two treatment programs. Although MC and GE exercises were distinctly different at the beginning of the intervention, there was an increasing similarity of exercises between the two programs as treatment progressed. MC treatment progression shifted from closed chain to open chain exercises, with incremental loading, introducing strengthening components. GE treatment focused on strength without specifically paying attention to movement control impairments. A second explanation for the non-significant differences in outcome may be that, in patients with positive $\mathrm{MCl}$ tests, the loss of movement control is not the only factor contributing to NSLBP. Treatments in this study focused on the physical functional impairment of movement. Through the addition of cognitive characteristics to subgroup definition and treatment, as recently proposed, predictive models and patient outcomes may improve (O'Sullivan, 2012). 


\section{Theoretical background}

The physiological and cognitive rationales for movement control exercise have not been widely validated and are based on smaller studies. The physiological rationale of reducing mechanical overload on connective tissue, caused by uncontrolled movements, has been proposed by Kavic (Kavcic et al., 2004). In the current study, the attempt to control the load through improved muscular coordination, which resulted in a reduction in the number of positive $\mathrm{MCl}$ tests and improved disability, was achieved with both types of intervention.

The intervention using MC exercises also addressed body and movement awareness, positive experiences with pain-free movement and explanations for the improved movement control. These cognitive aspects may have had a potential impact on the reorganisation of the cerebral cortex representing areas of the low back and on the reversal of central sensitisation processes in the nervous system (Nijs et al., 2010; Voss et al., 2010; Wand et al., 2011). However, questions about changes in the nervous system could not be answered in the current study.

\section{$\underline{\text { Conclusion }}$}

This randomized controlled trial, comparing 9-12 weeks of specific movement control training to general exercise, showed no difference in improvement of LBP disability. Future research should extend the criteria for the definition of clinical subgroups among patients with LBP, as well as further develop treatments focused on these subgroups. Distinctly different exercise programs are essential in future investigations concerning the question, "Which exercise is best for whom?". We recommend longitudinal studies to explore cognitive changes in patients with impaired movement control and NSLBP as well as treatment-induced biological changes. 


\section{Acknowledgements}

The authors wish to thank the physiotherapists, doctors and patients participating in this study. Without the immense support of clinicians, this study would not have been possible. Special acknowledgement and sincere thanks to Greet Mommen (MSc., scientific illustrator at Maastricht University, Dept. of Anatomy \& Embryology) for the illustrations of exercises in the appendix.

\section{Declaration of interest}

The project was supported by the Swiss National Science Foundation (SNSF). (Project no. 127240)

The trial was registered (ISRCTN80064281) and ethical approval obtained from the Swiss Ethics Committee KEK-ZH-NR: 2010-0034/5. The protocol has been published previously (Saner et al., 2011).

\section{$\underline{\text { References }}$}

Airaksinen O, Brox J, Cedraschi C, Hildebrandt J, Klaber-Moffett J, Kovacs F, Mannion A, Reis S, Staal J, Ursin H, Zanoli G 2006 Chapter 4. European guidelines for the management of chronic nonspecific low back pain. Eur Spine J 15 Suppl 2, S192-300.

Beurskens AJ, de Vet HC, Koke AJ, Lindeman E, van der Heijden GJ, Regtop W, Knipschild PG 1999 A patient-specific approach for measuring functional status in low back pain. J Manipulative Physiol Ther 22, 144-148.

Dankaerts W, O'Sullivan P 2011 The validity of O'Sullivan's classification system (CS) for a sub-group of NS-CLBP with motor control impairment $(\mathrm{MCl})$ : overview of a series of studies and review of the literature. Man Ther 16, 9-14.

Dankaerts W, O'Sullivan PB, Straker LM, Burnett AF, Skouen JS 2006 The inter-examiner reliability of a classification method for non-specific chronic low back pain patients with motor control impairment. Manual Therapy 11, 28-39.

Dworkin RH, Turk DC, McDermott MP, Peirce-Sandner S, Burke LB, Cowan P, Farrar JT, Hertz S, Raja SN, Rappaport BA, Rauschkolb C, Sampaio C 2009 Interpreting the clinical importance of group differences in chronic pain clinical trials: IMMPACT recommendations. Pain 146, 238-244.

Fersum KV, Dankaerts W, O'Sullivan PB, Maes J, Skouen JS, Bjordal JM, Kvale A 2009 Integration of sub-classification strategies in RCTs evaluating manual therapy treatment and exercise therapy for non-specific chronic low back pain (NSCLBP): a systematic review. Br J Sports Med. 
Fersum KV, Dankaerts W, O'Sullivan PB, Maes J, Skouen JS, Bjordal JM, Kvale A 2010 Integration of subclassification strategies in randomised controlled clinical trials evaluating manual therapy treatment and exercise therapy for non-specific chronic low back pain: a systematic review. $\mathrm{Br} \mathrm{J}$ Sports Med 44, 1054-1062.

Foster NE, Hill JC, Hay EM 2011 Subgrouping patients with low back pain in primary care: are we getting any better at it? Man Ther 16, 3-8.

Grob D, Frauenfelder H, Mannion AF 2007 The association between cervical spine curvature and neck pain. Eur Spine J 16, 669-678.

Hall AM, Maher CG, Latimer J, Ferreira ML, Costa LO 2011 The patient-specific functional scale is more responsive than the Roland Morris disability questionnaire when activity limitation is low. Eur Spine J 20, 79-86.

Hayden JA, van Tulder MW, Malmivaara A, Koes BW 2005a Exercise therapy for treatment of nonspecific low back pain. Cochrane Database Syst Rev, CD000335.

Hayden JA, van Tulder MW, Malmivaara AV, Koes BW 2005b Meta-analysis: exercise therapy for nonspecific low back pain. Ann Intern Med 142, 765-775.

Hayden JA, van Tulder MW, Tomlinson G 2005c Systematic review: strategies for using exercise therapy to improve outcomes in chronic low back pain. Ann Intern Med 142, 776-785.

Hides J, Stanton W 2012 Muscle imbalance among elite Australian rules football players: a longitudinal study of changes in trunk muscle size. J Athl Train 47, 314-319.

Horn KK, Jennings S, Richardson G, Vliet DV, Hefford C, Abbott JH 2012 The patient-specific functional scale: psychometrics, clinimetrics, and application as a clinical outcome measure. J Orthop Sports Phys Ther 42, 30-42.

Kavcic N, Grenier S, McGill SM 2004 Determining the stabilizing role of individual torso muscles during rehabilitation exercises. Spine (Phila Pa 1976) 29, 1254-1265.

Koumantakis GA, Watson PJ, Oldham JA 2005 Trunk muscle stabilization training plus general exercise versus general exercise only: randomized controlled trial of patients with recurrent low back pain. Phys Ther $85,209-225$.

Linton SJ, Boersma K 2003 Early identification of patients at risk of developing a persistent back problem: the predictive validity of the Orebro Musculoskeletal Pain Questionnaire. Clin J Pain 19, 8086.

Luomajoki H, Kool J, de Bruin ED, Airaksinen O 2007 Reliability of movement control tests in the lumbar spine. BMC Musculoskelet Disord 8, 90.

Luomajoki H, Kool J, de Bruin ED, Airaksinen O 2008 Movement control tests of the low back; evaluation of the difference between patients with low back pain and healthy controls. BMC Musculoskelet Disord 9, 170.

Luomajoki H, Kool J, de Bruin ED, Airaksinen O 2010 Improvement in low back movement control, decreased pain and disability, resulting from specific exercise intervention. Sports Med Arthrosc Rehabil Ther Technol 2, 11.

Mannion AF, Caporaso F, Pulkovski N, Sprott H 2010 Goal attainment scaling as a measure of treatment success after physiotherapy for chronic low back pain. Rheumatology (Oxford) 49, 17341738.

Maughan EF, Lewis JS 2010 Outcome measures in chronic low back pain. Eur Spine J 19, 1484-1494. Moseley GL 2008 I can't find it! Distorted body image and tactile dysfunction in patients with chronic back pain. Pain 140, 239-243.

Nijs J, Van Houdenhove B, Oostendorp RA 2010 Recognition of central sensitization in patients with musculoskeletal pain: Application of pain neurophysiology in manual therapy practice. Man Ther 15, 135-141.

O'Sullivan P 2005 Diagnosis and classification of chronic low back pain disorders: Maladaptive movement and motor control impairments as underlying mechanism. Manual Therapy 10, 242-255. O'Sullivan P 2012 It's time for change with the management of non-specific chronic low back pain. $\mathrm{Br}$ J Sports Med 46, 224-227. 
Pengel LH, Refshauge KM, Maher CG 2004 Responsiveness of pain, disability, and physical impairment outcomes in patients with low back pain. Spine (Phila Pa 1976) 29, 879-883.

Saner J, Kool J, de Bie RA, Sieben JM, Luomajoki H 2011 Movement control exercise versus general exercise to reduce disability in patients with low back pain and movement control impairment. A randomised controlled trial. BMC Musculoskelet Disord 12, 207.

Sieben JM, Vlaeyen JW, Portegijs PJ, Verbunt JA, van Riet-Rutgers S, Kester AD, Von Korff M, Arntz A, Knottnerus JA 2005 A longitudinal study on the predictive validity of the fear-avoidance model in low back pain. Pain 117, 162-170.

SNF SN 2009 Muskuloskelettale Gesundheit - Chronische Schmerzen, NFP 53, Synthesebericht der Leitungsgruppe. Schweizerischer Nationalfonds SNF Abteilung IV, Orientierte Forschung.

Solomonow M, Baratta RV, Banks A, Freudenberger C, Zhou BH 2003 Flexion-relaxation response to static lumbar flexion in males and females. Clin Biomech (Bristol, Avon) 18, 273-279.

Solomonow M, Eversull E, He Zhou B, Baratta RV, Zhu MP 2001 Neuromuscular neutral zones associated with viscoelastic hysteresis during cyclic lumbar flexion. Spine (Phila Pa 1976) 26, E314324.

Staerkle R, Mannion AF, Elfering A, Junge A, Semmer NK, Jacobshagen N, Grob D, Dvorak J, Boos N 2004 Longitudinal validation of the fear-avoidance beliefs questionnaire (FABQ) in a Swiss-German sample of low back pain patients. Eur Spine J 13, 332-340.

Stratford P GC, Westaway M, Binkley J, 1995 Assessing disability and change on individual patients: a report of a patient specific measure. Physiother Canada 47, 258-263.

Turk DC, Melzack, R. 2011 Handbook of pain assessment. The Guildford Press.

Voss MW, Prakash RS, Erickson KI, Basak C, Chaddock L, Kim JS, Alves H, Heo S, Szabo AN, White SM, Wojcicki TR, Mailey EL, Gothe N, Olson EA, McAuley E, Kramer AF 2010 Plasticity of brain networks in a randomized intervention trial of exercise training in older adults. Front Aging Neurosci 2.

Wand BM, Parkitny L, O'Connell NE, Luomajoki H, McAuley JH, Thacker M, Moseley GL 2011 Cortical changes in chronic low back pain: current state of the art and implications for clinical practice. Man Ther 16, 15-20.

Whaley MH 2006 ACSM's Guidelines for exercise testing and prescription, in: Medicine ACoS (Ed.). Lippincott Williams \&Wilkins. 
Figure 1 Flow chart of participants through the trial

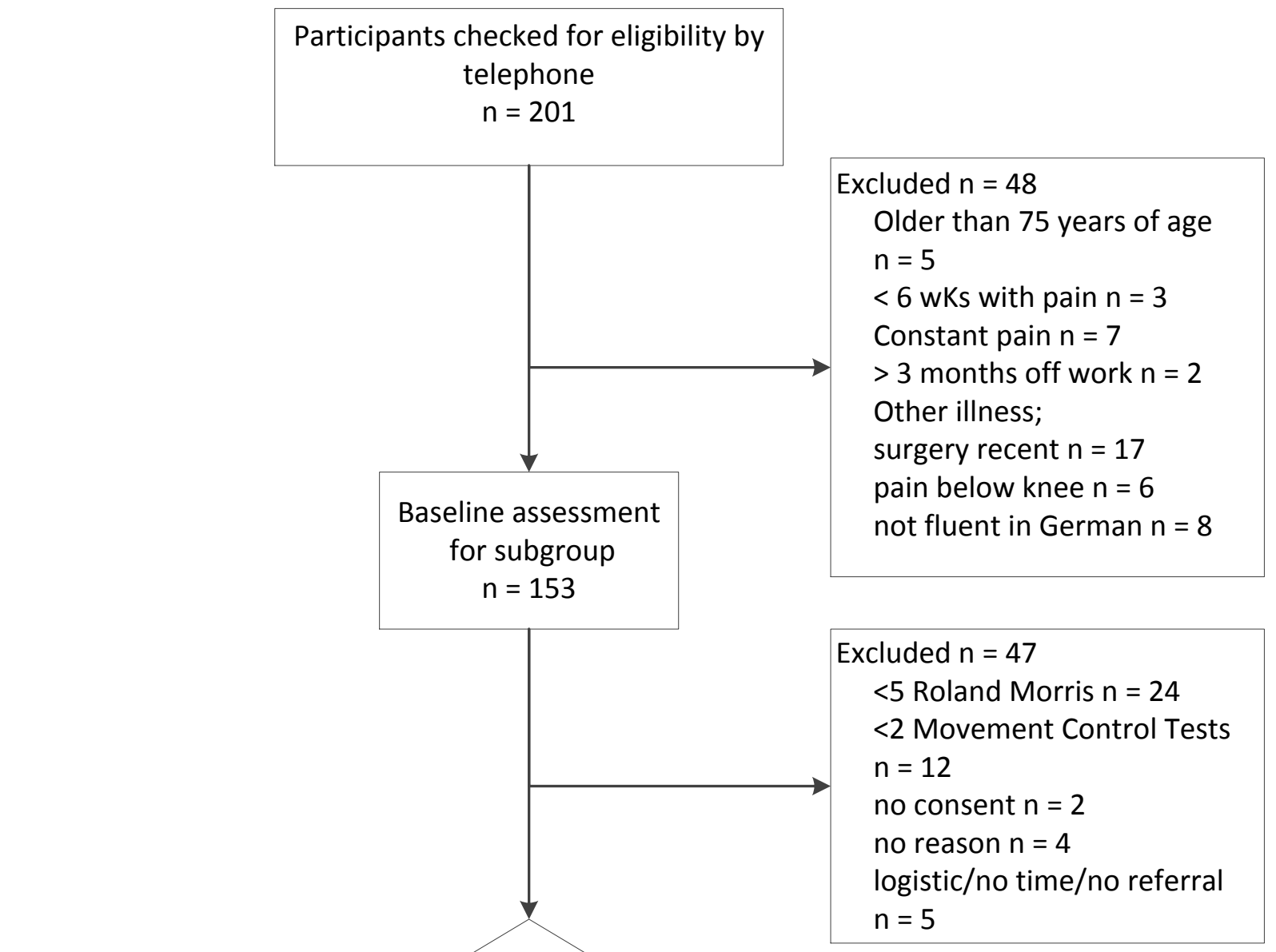

Eligible subjects randomised

$\mathrm{n}=106$

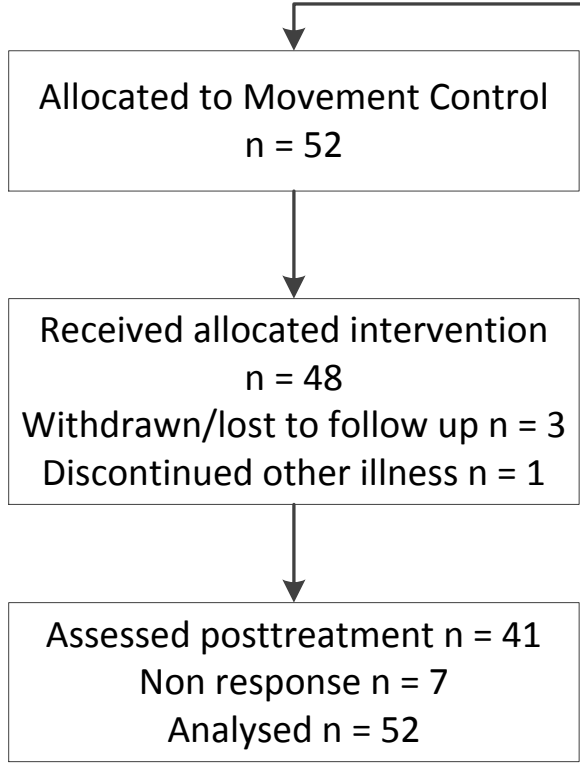

Allocated to General Exercise $n=54$

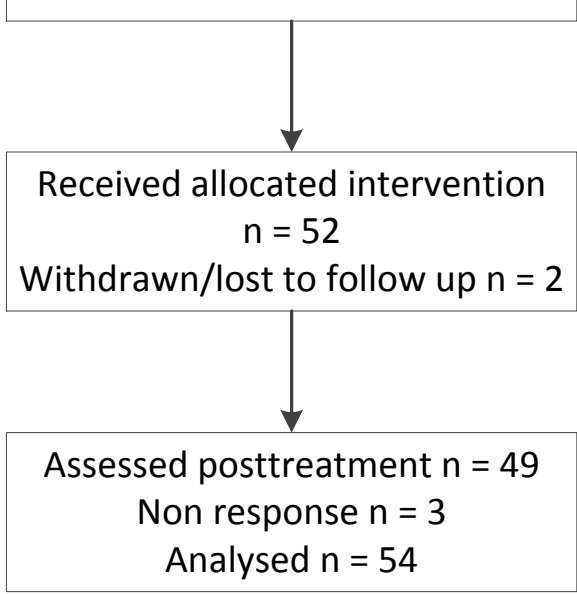


Table 1 Baseline demographic data and baseline results of questionnaires

\begin{tabular}{|c|c|c|c|c|}
\hline & & $\begin{array}{c}\text { Movement } \\
\text { Control } \\
n=52\end{array}$ & $\begin{array}{c}\text { General } \\
\text { Exercise } \\
n=54\end{array}$ & $\begin{array}{c}\text { Total } \\
\text { Group } \\
\mathrm{n}=106\end{array}$ \\
\hline Age (y) & mean (SD) & $42.8(13.8)$ & $40.5(14.7)$ & $41.6(1.4)$ \\
\hline Gender & female, $\mathrm{n}$ & 16 & 24 & 40 \\
\hline Height $(\mathrm{cm})$ & mean (SD) & $173.0(8.5)$ & $173.9(8.0)$ & $173.6(8.3)$ \\
\hline Weight (kg) & mean (SD) & $75.5(11.7)$ & $74.7(11.9)$ & $75.4(12.1)$ \\
\hline \multirow[t]{4}{*}{ Physical workload } & low, n & 23 (44.2\%) & $21(38.9 \%)$ & $44(41.5 \%)$ \\
\hline & medium, $\mathrm{n}$ & $22(42.3 \%)$ & $26(48.1 \%)$ & $48(45.3 \%)$ \\
\hline & heavy, $n$ & $5(9.6 \%)$ & $6(11.1 \%)$ & $11(10.4 \%)$ \\
\hline & missing, $\mathrm{n}$ & $2(3.8 \%)$ & $1(1.9 \%)$ & $3(2.8 \%)$ \\
\hline \multirow[t]{4}{*}{ Sport participation } & No, $n$ & $19(36.5 \%)$ & $16(30.8 \%)$ & 35 (33.0\%) \\
\hline & $1-2 x$ week, $n$ & $21(42.0 \%)$ & $23(43.1 \%)$ & $44(41.5 \%)$ \\
\hline & $>2 x$ week, $n$ & $10(20.0 \%)$ & $13(25.0 \%)$ & $23(21.7 \%)$ \\
\hline & missing, $n$ & $2(3.8 \%)$ & $2(3.8 \%)$ & 4 (3.8\%) \\
\hline \multirow[t]{5}{*}{ Work status } & sick leave, $\mathrm{n}$ & $1(1.9 \%)$ & $5(9.3 \%)$ & $6(5.7 \%)$ \\
\hline & $\begin{array}{l}\text { part-time } \\
\text { leave, } n\end{array}$ & $3(5.8 \%)$ & $3(5.6 \%)$ & $6(5.7 \%)$ \\
\hline & full-time, $n$ & 39 (75.0\%) & 38 (70.4\%) & 77 (72.6\%) \\
\hline & no paid job, n & $5(9.6 \%)$ & $8(14.8 \%)$ & $13(12.3 \%)$ \\
\hline & missing, $\mathrm{n}$ & $4(7.7 \%)$ & 0 & $4(3.8 \%)$ \\
\hline \multirow[t]{5}{*}{ Pain Duration $^{*}(\mathrm{y})$} & mean (SD) & $11.6(12.8)$ & $8.4(8.9)$ & $10.0(11.0)$ \\
\hline & $<1$ year, $\mathrm{n}$ & 4 & 8 & $12(11.3 \%)$ \\
\hline & $1-5$ years, $n$ & 17 & 15 & $32(30.2 \%)$ \\
\hline & $>5$ years, $\mathrm{n}$ & 26 & 27 & $53(50.0 \%)$ \\
\hline & missing, $n$ & 5 & 4 & $9(8.5 \%)$ \\
\hline ÖMPQ & mean (SD) & $78.3(24.3)$ & $81.5(20.4)$ & 79.9 (22.3) \\
\hline \multirow[t]{3}{*}{ FABQ Total } & mean (SD) & $29.9(13.7)$ & $34.7(15.4)$ & $32.3(14.7)$ \\
\hline & missing, $\mathrm{n}$ & $2(3.8 \%)$ & $3(5.6 \%)$ & $5(4.7 \%)$ \\
\hline & mean (SD) & $25.9(9.8)$ & $29.5(11.0)$ & $27.8(10.4)$ \\
\hline $\begin{array}{l}\text { GCPS Pain } \\
\text { Intensity score }\end{array}$ & mean (SD) & $14.7(4.7)$ & $16.5(4.2)$ & $15.6(4.5)$ \\
\hline $\begin{array}{l}\text { GCPS Disability } \\
\text { score }\end{array}$ & mean (SD) & $11.5(7.2)$ & $13.3(8.3)$ & $12.4(7.6)$ \\
\hline \multirow[t]{5}{*}{$\begin{array}{l}\text { GCPS Chronic } \\
\text { Pain score }\end{array}$} & Grade I, $\mathrm{n}$ & $21(41.2 \%)$ & $16(30.8 \%)$ & 37 (35.9\%) \\
\hline & Grade II, $\mathrm{n}$ & 17 (33.3\%) & $20(38.5 \%)$ & 37 (35.9\%) \\
\hline & Grade III, $\mathrm{n}$ & $10(19.6 \%)$ & $11(21.2 \%)$ & $21(20.4 \%)$ \\
\hline & Grade IV, $\mathrm{n}$ & $3(5.9 \%)$ & $5(9.6 \%)$ & $8(7.8 \%)$ \\
\hline & missing, $\mathrm{n}$ & $1(1.9 \%)$ & $2(3.7 \%)$ & $3(2.8 \%)$ \\
\hline
\end{tabular}

\footnotetext{
* Overall duration of LBP
} 
ÖMPQ: Oerebrö musculoskeletal pain questionnaire (Linton \& Boersma, 2003) FABQ: Fear-avoidance beliefs questionnaire - 0 (low fear); 96 (highest fear) (Sieben et al., 2005; Staerkle et al., 2004)

GCPS: Graded Chronic Pain Scale: subscale for pain (0-30); subscale for disability (0-40); subscale for pain grade ( $0-I V ; 0=$ no pain, no disability; IV=high disability) (Turk, 2011) 
Table 2 Results of disability scores pre- and post-treatment and between-group differences

\begin{tabular}{|l|l|l|l|l|l|l|}
\hline & \multicolumn{2}{|l|}{$\begin{array}{l}\text { Pre- } \\
\text { treatment }\end{array}$} & \multicolumn{3}{|l|}{ Post-treatment } & \multicolumn{2}{|l|}{$\begin{array}{l}\text { Difference between groups } \\
\text { post-treatment (change } \\
\text { scores pre-post-treatment) }\end{array}$} \\
\hline Outcomes & $\begin{array}{l}\text { MC } \\
(\mathrm{n}=52) \\
\text { mean } \\
(\mathrm{SD})\end{array}$ & $\begin{array}{l}\text { GE } \\
(\mathrm{n}=54) \\
\text { mean (SD) }\end{array}$ & $\begin{array}{l}\text { MC } \\
(\mathrm{n}=52) \\
\text { mean (SD) }\end{array}$ & $\begin{array}{l}\text { GE } \\
(\mathrm{n}=54) \\
\text { mean (SD) }\end{array}$ & $\begin{array}{l}\text { Mean (SD, } \\
95 \% \mathrm{Cl})\end{array}$ & p-value \\
\hline PSFS activity1 & $4.3(1.9)$ & $4.0(2.0)$ & $7.4(1.9)$ & $6.6(2.2)$ & $\begin{array}{l}0.5(0.5)-0.5- \\
1.5\end{array}$ & 0.32 \\
\hline RMDQ & $9.1(3.2)$ & $8.2(3.3)$ & $4.2(3.7)$ & $5.2(4.0)$ & $2.0(0.8) 0.4-3.5$ & $0.01^{* *}$ \\
\hline
\end{tabular}

MC: Movement control group GE: General exercise group

PSFS: Patient-Specific Functional Scale self-score activity mentioned first, ranging from 0 (unable to perform) to 10 (able to perform without difficulties)

RMDQ: Roland-Morris Disability Questionnaire score, ranging from 0 (no difficulties) to 24 (extreme difficulties)

SD: standard deviation. Cl: confidence interval 
Table 3 Patients with a minimal clinically important difference post-treatment; relative risk and number needed to treat (NNT) for clinical important improvement

\begin{tabular}{|l|l|l|l|l|l|}
\hline Outcomes & $\begin{array}{l}\text { Total group } \\
(n=106) n(\%)\end{array}$ & $\begin{array}{l}\text { MC group } \\
(n=52) n(\%)\end{array}$ & $\begin{array}{l}\text { GE group } \\
(n=54) n(\%)\end{array}$ & $\begin{array}{l}\text { Relative risk } \\
(95 \% C l)\end{array}$ & NNT \\
\hline PSFS & $73(68.9)$ & $40(76.9)$ & $33(61.1)$ & $1.25(0.97-1.42)$ & 7 \\
\hline RMDQ & $70(66.0)$ & $40(76.9)$ & $30(55.6)$ & $\begin{array}{l}1.39(1.04- \\
1.83)\end{array}$ & 5 \\
\hline
\end{tabular}

MC: Movement control group; GE: General exercise group; PSFS: Patient-Specific Functional Scale; RMDQ: Roland-Morris Disability Questionnaire; Cl: confidence interval; NNT: numbers needed to treat 